\title{
Facilitating Retention and Transfer of Physics Concepts with Challenging Assignments in Design-Based Learning Projects
}

\author{
Sonia Maria Gomez Puente1, Gerrit M. W. Kroesen² \\ ${ }^{1}$ Industrial Design Department, Eindhoven University of Technology (TU/e), Eindhoven, The Netherlands \\ ${ }^{2}$ Applied Physics Department, Eindhoven University of Technology (TU/e), Eindhoven, The Netherlands \\ Email: s.m.gomez.puente@tue.nl, g.m.w.kroesen@tue.nl
}

How to cite this paper: Gomez Puente, S. M., \& Kroesen, G. M. W. (2020). Facilitating Retention and Transfer of Physics Concepts with Challenging Assignments in DesignBased Learning Projects. Open Journal of Social Sciences, 8, 366-387.

https://doi.org/10.4236/jss.2020.812030

Received: November 8, 2020

Accepted: December 26, 2020

Published: December 29, 2020

Copyright () 2020 by author(s) and Scientific Research Publishing Inc. This work is licensed under the Creative Commons Attribution International License (CC BY 4.0).

http://creativecommons.org/licenses/by/4.0/

\begin{abstract}
Retention and transfer of information were tested in a second-year bachelor design-based learning project, and compared with a traditional bachelor level course. The project Signal and Systems is a core and compulsory course within the physics curriculum of the Applied Physics Department at the Eindhoven University of Technology, the Netherlands. Students from different year-level cohorts participated in a study consisting of a 15-open question test on systems, control technology, and Laplace transform. Students' perceptions of active learning educational factors that may support understanding and the retention and transfer of information were also measured. A small number of students were interviewed in focus groups to validate the data on elements that promote retention and transfer. Results indicate that students following the design-based learning project recorded higher median marks in their assignments compared to those enrolled in the traditional course. Students from all cohorts agreed that the educational factors promoting learning were repetition of topics throughout the bachelor curriculum, practicing and providing feedback, and an explanation on errors made. Results from this study serve as a suitable example for tertiary educational practitioners to use design-based learning to facilitate retention and transfer.
\end{abstract}

\section{Keywords}

Retention, Transfer, Design-Based Learning, Challenge-Based Learning, Active Learning

\section{Introduction}

One of the ultimate goals in education is to prepare students not only to perform 
specific tasks and recall factual information, but also to apply the knowledge and skills learned in previous courses. Ideally, students are empowered to transfer knowledge and skills to apply them in new contexts and in the workplace. This critical goal of education fosters educational achievement and stimulates lifelong learning (Bransford \& Schwartz, 1999). Enhancing the retention of learned information lies at the heart of all educational systems (Bransford \& Schwartz, 1999; Deslauriers, Schelew, \& Wieman, 2011). The traditional belief that retention and transfer have mainly to do with teaching content (Mason \& Singh, 2010; Singh, 2002), contrasts with current studies supporting that educational factors such as active learning approaches can also facilitate retention and transfer (Lucas et al., 2013; Ozimek et al., 2005).

This study reports on second-year tertiary students' abilities to retain and transfer concepts in the field of control technology in a Design-based learning (DBL) project entitled Signals and Systems at the Applied Physics Department at Eindhoven University of Technology, the Netherlands. The purpose of this study is to investigate to what extent the DBL approach facilitates the retention of concepts of control technology in comparison to the traditional course Signal and Systems. The focus of this study aims at shedding light on the factors that influence retention and transfer of conceptual understanding in physics. The study also explored the educational factors that may facilitate and influence the retention and transfer of information as perceived by the students.

\section{Literature Review}

Knowledge retention and the transfer of knowledge and skills in different contexts remain as one of the main interests of all educational practitioners and educational institutions (Larsen-Freeman, 2013; Marx \& Cummings, 2007; Cummings, Lockwood, \& Marx, 2004). Information retention and transfer are at the center of educational research as one of the means to measure quality of education (McKeough et al., 1995).

From the "formal discipline" theories of learning and retention from the past century (Judd, 1908; Wertheimer, 1959); to the current practices (Elby, 2001; Gegenfurtner, 2013; Mason et al., 2008), much has been investigated about the retention and transfer of conceptual understanding (Spiro, Vispoel, Thorndike, \& Woodworth, 1901). Experimental research points out several principles that enhance retention, but also conditions that hinder learning (Anderson, Reder, \& Simon, 1997; Lee, 1998). One of the premises that arise from research is that performing optimally in a knowledge test does not necessarily mean that the knowledge learned before can easily be transferred to a new context and situation (Wertheimer, 1959; Bransford \& Schwartz, 1999). Furthermore, contemporary literature emphasizes the shift from teaching to learning and the importance of paying attention to how to learn, instead of what content to teach in order to foster conceptual understanding and facilitate retention and transfer (Elby, 2001; Marx \& Cummings, 2007; Karelina \& Etkina, 2007). 
In addition, many of the methods currently used to assess learning such as memory testing (Spiro, Vispoel, Thorndike, \& Woodworth, 1901) and testing on facts (Adams et al., 1988), primarily test students after completion of courses, despite the fact that some studies confirm the loss of factual knowledge within a period of a year (Bacon \& Stewart, 2006). These assessment methods primarily comply with the need to prove evidence of academic attainment regulations, rather than assessing the long-term retention and transfer of that learning.

For the purpose of this study, some contemporary definitions of "retention" will refer to the degree to which a student can remember, summarize or reproduce fundamental concepts (rather than facts) and the contents of the subject (Ozimek et al., 2005: p. 173). "Transfer" is defined in this study as the extent to which one can apply what was learned in one situation to a new situation (Ozimek et al., 2005: p. 173).

\section{Research on Promoting Deep Learning}

Research on retention and transfer is extensive and has raised some interesting observations about successful experiences (Gick \& Holyoak, 1983; Bransford et al., 1999) just as failures in this field highlight the educational elements that add less value to retention and transfer practices (Bjork \& Richardson-Klavhen, 1989; Gick \& Holyoak, 1980). Research in conceptual understanding highlights "learning with understanding" as one of the values that enhances performance on the transfer of tasks, rather than following procedures to solve problems (Singley \& Anderson, 1989; Bransford \& Schwartz, 1999). Despite the process to transfer knowledge and skills from a structured domain into an unstructured context implies the application of heuristics (Veermans, van Joolingen, \& de Jong, 2006; Kryjevskaia, MacKenzie, \& Grosz, 2014); experts highlight the difficulties students have to learn and create high-order skills schemas to allow them to transfer learning into new situations (McKagan \& Wieman, 2006; Deslauriers, Schelew, \& Wieman, 2011).

Literature strongly argues that active learning approaches promote retention and stimulates transfer of conceptual knowledge when applied in problem solving situations (Jonassen, 2011; Barron et al., 1998). Similarly, studies show that instruction that engages students actively in interactive classroom activities and provides formative assessment (assessment for learning), resulting in better conceptual learning than the one achieved by a highly rated traditional lecturer (Kang, McDermont, \& Roediger, 2007; Deslauriers, Schelew, \& Wieman, 2011). Experiences in the conceptual understanding in physics education dominate the literature (McConnell et al., 2006; Miller et al., 2013). Educational practitioners in the field of physics (Hake, 1998; Tew \& Guzdial, 2010) have conducted numerous studies to report how interactive audio response devices enhance levels of students' learnings from content presented in traditional lectures and demonstrations of conceptual understanding. Examples of measuring students' information retention in classroom demonstrations, have been shown by promoting engagement and deep learning (Crouch \& Mazur, 2001; Mazur, 2009; Direnga et 
al., 2015), and these studies emphasize that active learning approaches facilitate the understanding of concepts. However, this practice is in direct contrast with the concern of other educational practitioners that students do not learn standard content from textbooks properly when working with more open, authentic and complex tasks (Moreno, 2004; Kirschner, Sweller, \& Clark, 2006). The dilemma lies in that complex tasks might not cover all the standard knowledge students need to learn in a course.

Students' achievements with the use of active learning methods such as design-based learning, problem/project-based akin approaches are well documented in research (Fortus et al., 2004; Gómez Puente, van Eijck, \& Jochems, 2013; Gómez Puente, van Eijck, \& Jochems 2014). Studies demonstrate that project work and similar approaches stimulate a deeper approach to learning, helping students retain knowledge longer than traditional instruction (Lucas et al., 2013; Prince, 2004). The theoretical considerations behind active learning that promote retention and transfer confront students with open-ended scenarios. These unstructured assignments offer opportunities to explore, analyze, test options, and consider alternatives iteratively for further exploration (Gómez Puente, van Eijck, \& Jochems, 2013). By visualizing problems, looking for alternatives and using reasoning to construct solutions from multiple perspectives, stimulates transfer and deep thinking (Jonassen, 2000).

In this study, the focus was on the information retention and transfer regarding concepts of control technology, fundamental within the Signals and Systems course. In particular, how students transferred these concepts in solving similar problems sometime later were measured. In addition, levels of students' satisfaction regarding educational factors, i.e. course organization, teaching methods, teachers' competencies, feedback, were measured that may facilitate retention and transfer in the traditional course and the DBL project. Finally, these findings were verified with the students participating in the study.

\section{Theoretical Considerations}

\section{Design-Based Learning: Definitions and Key Characteristics}

Design-based Learning (DBL) is an educational concept for engineering education, as design is extensively used in engineering disciplines (Lawson \& Dorst, 2009; Gómez Puente, van Eijck, \& Jochems 2011; Svensson, 2016; Chase, Malkiewich, \& Kumar, 2019). DBL, as problem-based learning and project-organized learning, receives increased interest in technical universities as a result of a worldwide trend advocating for the transition towards more learner-centered curricula in higher education (Lamancusa, 2006; Sheppard et al., 2008). In DBL assignments students gather and apply knowledge in the design of artifacts, systems, and innovative solutions in project settings (Wijnen, 2000). This approach is used to enhance the skills and knowledge required for complex activities conducted, mainly, in group work. DBL projects encourage students to solve challenging and hands-on assignments often within multidisciplinary or interdiscip- 
linary domains. DBL is grounded in active learning approaches, such as learning by design (LBD) (Kolodner, 2002; Kolodner et al., 2003), and design-based science (DBS) (Fortus et al., 2004). From the results of these studies, DBL has appeared to be a promising method to teach science concepts (Apedoe et al., 2008; Doppelt et al., 2008). DBL emphasizes planning and making decisions as students go through iterations in generating ideas based on predictions, experiencing and creating solutions, testing and communicating (Doppelt et al., 2008) while engaging students in authentic and challenging sciences and engineering design assignments (Mehalik, Doppelt, \& Schunn, 2008).

In DBL, the situated learning theory is central to engage students in authentic learning, hence students work in scenarios including practices that resemble how scientists and engineers work in real life. In the engineering education literature, there are numerous examples of situated learning practices having students working in tasks to solve ill-defined problems where cognitive processes are represented by how engineers think and iteratively approach design tasks related to scoping the problem, making estimates and dealing with ambiguity, conducting experiments, and making decisions by evaluating results to meet the needs of the users (Atman et al., 2007; Dym \& Little, 2003). Characteristic of these scenarios is oftentimes the work on open-ended and hands-on experiences, approaching problems from multiple user's perspectives (Dym et al., 2003; Lawson \& Dorst, 2009). Based on previous research (Gómez Puente, van Eijck, \& Jochems 2013), DBL is framed in five dimensions, namely, project characteristics i.e. open-ended, hands-on, authentic and multi- or interdisciplinary (Behrens et al., 2010), hands-on (Martínez Monés et al., 2005); design activities of DBL framework that engineers undertake are adopted from a classification of fifteen design elements from industrial contexts (Mehalik \& Schunn, 2006); the teachers role in student supervising and scaffolding the thinking process by asking open-ended questions, encouraging reflection and supporting students in analyzing design problems from different perspectives (Etkina et al., 2010), providing formative feedback; assessment, design processes are assessed by rubrics (Etkina, Murthy, \& Zou, 2006) and through mid-term products and prototypes, oftentimes with the involvement of the industry. Finally, the social context encounters collaborative learning environments in which students give feedback to each other (Chang et al., 2008) and communicate and practice engineering terminology (Denayer et al., 2003).

The design-based learning assignment of the Signal and Systems project comprises challenge-oriented tasks in which students work in authentic, open-ended problems requesting to provide a solution relevant for the society. The term Challenge-based learning (CBL) is oftentimes used to define learning environments that engage students in societal, business, technological and value-driven practices (Malmqvist, Rådberg, \& Lundqvist, 2015). CBL shares educational principles with problem-based learning and alike collaborative approaches, and it also comprises some specific characteristics as it centers around societal dilemmas while addressing sustainability, going from technical systems into the 
socio-technical system domain (Tight, 2020; Malmqvist, Rådberg, \& Lundqvist, 2015). From that perspective, the Signal and Systems design-based learning project comprises challenging tasks as students solve a social and industry-oriented problem.

\section{Research Questions}

Literature has pointed out the relevance of active learning methods that facilitate understanding of concepts. Specially, project-based and design-based learning approaches can be of significant importance that help students learning. Based on this literature review, the following research questions framed this research study:

1) To what extent does the DBL approach facilitate the retention of concepts of control technology in comparison to the traditional course Signal and Systems?

2) What are the educational factors as perceived by the students that may facilitate retention and transfer?

3) What are students' perceptions about the factors that influence retention and transfer?

The hypothesis was that the integration of challenging assignment with the DBL projects will enhance students' retention and transfer of conceptual knowledge.

\section{Method}

\section{Challenge-Oriented and Design-Based Learning: The Instructional Design of Signal and Systems Project}

The course Systems and Control was a traditional second-year bachelor physics course (2015/2016) combining topics such as signal theory. This course was part of the core curriculum of the Applied Physics department for many years and included traditional lectures, or "frontal" teaching, supported by instructions in which students worked on scenario tasks. The assessment method of this course was a written examination consisting of open questions and lab assignments. A hands-on research component was included in this course, which turned the name of the course into Signals and Systems. In this course, traditional lectures were combined with laboratory work (i.e. practical exercises in a lab). The lab assignment consisted of building a pre-described control system, following a sequence of detailed steps that lead incrementally through the actions required to get the system working.

Curriculum requirements led to a new iteration in the Signals and Systems course. In 2016/2017 the course was divided into two different courses "Elements of Mathematical Physics" and the project "Signal and Systems". Elements of Mathematical Physics was a teacher-centered course devoted to teaching students the fundamentals of mathematical applications in the context of physics. The course comprised lectures and practical lab work. The innovative character 
of the project Signals and Systems was the inclusion of a challenge focusing on control technology. The aim of the DBL Signals and Systems project was to explore systems to maintain a Maglev train levitating by experimenting with repulsion forces between the magnets in the train and the electromagnetics in the track.

The instructional design of Signal and Systems project was based on a challenge-oriented set-up and Design-based learning (DBL) approach (Kunnen, Kroesen, \& Gómez Puente, 2018) that challenged students to model a physical system, experiment with the levitation of a ball by measuring pull-up and pull-down forces and design, optimize and build a control system (see Figure 1, Figure 2). Students learned through hands-on and open-ended design-based process by exploring how a control system works, reviewing stabilization time, experimenting with calibration, using physics concepts to design and build a magnetic levitation system that can be used for Maglev trains. The innovative character of this project was that the assignment brought about opportunities for the students to acquire and apply disciplinary knowledge, and not only professional skills, e.g. collaboration, communication, and, planning and organization skills.

Subsequent changes took place in the set-up of the DBL project Signals and Systems (2017/2018) and challenging assignments were included, where the
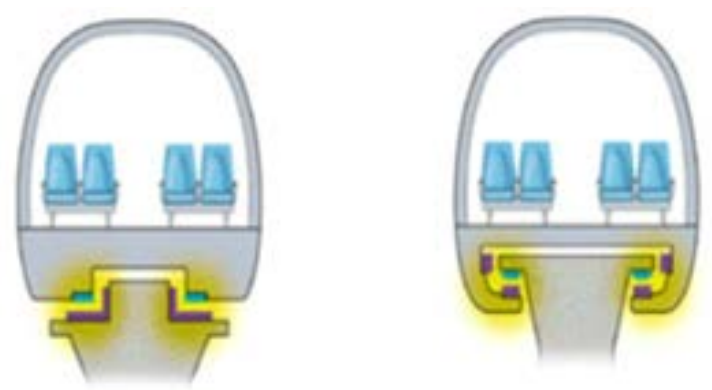

Figure 1. (Left) Electromagnets on the guideway levitate the car; (Right) Electromagnets on the cars lift the cars.

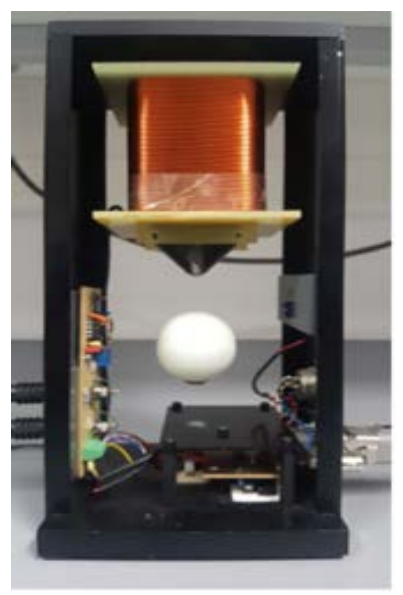

Figure 2. Magnetic levitation system (console). 
interdisciplinary elements from the Mechanical Engineering (ME) and Electrical Engineering (EE) fields were introduced. Subjects from the Electrical Engineering field such as the extension to the fully digital domain, Z-transform and the pole manipulation in the digital (z-transform) domain were also integrated. From the Mechanical Engineering discipline, topics concerning the frequency domain, recording a Bode plot of the open system, optimizing control action from that viewpoint were also added. The challenge consisted of having students to start with the system with open loop stable (upside-down configuration: electromagnet is below permanent magnet, pushing the permanent magnet upwards), optimizing and later extending this towards the "normal" configuration, with the electromagnet magnet above the permanent magnet, pulling it up, where the open loop is unstable, and an open loop Bode diagram cannot be recorded. Short introductory lectures served to present new concepts on EE and ME disciplinary topics in order to widen students' understandings on those. The open-ended character provided students with insights on EE and ME subjects. As in an iterative cycle, students experimented with these topics by testing and analyzing and based on results apply new gains iteratively in the models. By doing so, students gathered new information and facts in each design step and made use of this new knowledge in order to generate and produce new insights. The rationale to integrate EE and ME disciplinary subjects was not only based on including elements of these disciplines, but also to stimulate a rather trial-and-error approach to problems and look for solutions. On the contrary, the physicists' approach followed a rather linear process to analyze physical models using differential equations and Laplace transformation.

This pilot was carried out with 22 students' groups about 7 to 8 students in each group within the Innovation Space environment. The Innovation Space is a learning open space aiming at having students from different disciplines to work collaborative in socially-relevant projects. An additional goal was to create linkages with the industry, research organizations and businesses in order to develop an ecosystem of technological development. The successful experience of the suitability of interdisciplinary challenging project showed that the quality of the measurements and simulations comparing the groups who did not have interdisciplinary and Innovation Space influence was not very different from one to another. However, the quality of the analysis of the Innovation Space groups with interdisciplinary added assignment was much better (authors). Table 1 reflects the different transformations made in the course Systems and Control and the DBL project Signals and Systems and provides an overview of the modifications and the time span to measure retention and transfer.

Based on this positive experience, the interdisciplinary components were maintained in the subsequent iteration of the Signals and Systems DBL project. However, following the feedback received from the students' evaluations together with the interest of testing individual knowledge, interim multiple-choice individual test was introduced (2018/2019). 
Table 1. Overview of Signal and Systems changes in the course/project throughout academic years.

\begin{tabular}{|c|c|c|c|c|c|}
\hline Year & $\begin{array}{l}\text { Educational set-up of } \\
\text { course/project }\end{array}$ & $\begin{array}{l}\text { Instructional design of the } \\
\text { course }\end{array}$ & $\begin{array}{l}\text { Assessment form of the } \\
\text { course }\end{array}$ & Modifications & $\begin{array}{l}\text { Time span after } \\
\text { completion course- } \\
\text { Measurement } \\
\text { Retention } \\
\text { \& Transfer }\end{array}$ \\
\hline $2015 / 2016$ & $\begin{array}{c}\text { Traditional set-up: } \\
2 \mathrm{~h} \text { lectures } 2 \mathrm{x} \text { a week } \\
2 \mathrm{~h} \text { instruction } 2 \mathrm{x} \text { a week }\end{array}$ & $\begin{array}{l}\text { Lectures to teach content. } \\
\text { Instructions: students work } \\
\text { individually or in pairs on } \\
\text { assignments } \\
\text { Plenary feedback }\end{array}$ & $\begin{array}{c}\text { Written exams } 75 \% \\
\text { Lab assignments (practical) } \\
25 \%\end{array}$ & & 2 years \\
\hline $2016 / 2017$ & $\begin{array}{c}\text { DBL-project } \\
4 \text { h a week } 2 \text { times in } \\
\text { groups (max. } 7 \text { students) }\end{array}$ & $\begin{array}{l}\text { Design-based learning: } \\
\text { group work }\end{array}$ & $\begin{array}{l}\text { Interim group report } 20 \% \\
\text { Individual grade/contribution } \\
\text { to project/peer review } 20 \% \\
\text { Final group report } 60 \%\end{array}$ & $\begin{array}{l}\text { From traditional lectures to } \\
\text { Challenge-based/DBL } \\
\text { project group }\end{array}$ & 1 year \\
\hline $2017 / 2018$ & $\begin{array}{c}\text { DBL-project } \\
4 \text { h a week } 2 \text { times in } \\
\text { groups (max. } 7 \text { students) }\end{array}$ & $\begin{array}{l}\text { Design-based learning: } \\
\text { group work }\end{array}$ & $\begin{array}{c}\text { Planning } 10 \% \\
\text { Individual grade } 30 \% \\
\text { Group grade (final report) } \\
60 \%\end{array}$ & $\begin{array}{c}\text { Project groups in } \\
\text { Innovation Space } \\
\text { (Pilot with } 4 \text { groups) } \\
\text { including multidisciplinary } \\
\text { components }\end{array}$ & 3 months \\
\hline $2018 / 2019$ & $\begin{array}{c}\text { DBL-project } \\
4 \text { h a week } 2 \text { times in } \\
\text { groups (max. } 7 \text { students) }\end{array}$ & $\begin{array}{l}\text { Design-based learning: } \\
\text { group work }\end{array}$ & $\begin{array}{c}\text { Mid-term individual exam } \\
20 \% \\
\text { Final group report } 60 \% \\
\text { Peer review } 20 \%\end{array}$ & $\begin{array}{l}\text { DBL projects in } \\
\text { Innovation Space } \\
\text { all groups } \\
\text { Individual test } \\
\text { knowledge exam }\end{array}$ & 3 months \\
\hline
\end{tabular}

\section{Research Study}

\subsection{Research Method and Development of Research Tools}

The research process has been carefully designed to include both quantitative (Plonsky \& Gass, 2011) and qualitative (McCusker \& Gunaydin, 2015) methods which were used to triangulate the results. The design of the test encompassed questions covering the study material given in the course Systems and Control in previous years. For the DBL project form of the course Signals and Systems, the same study material was provided in the form of self-study topics that the students needed to learn and practice to understand what the concepts were about. To assess students' retention and transfer on conceptual understanding of control technology, some assignments consisting of open questions on subject matter regarding Bode diagram, the benefits of a Simulink-Matlab environment, the meaning of an open-loop transfer function were prepared. Some examples of the questions in the test were: What are the effects of increasing the proportional action with a P-regulation?; What is meant by "the open loop transfer function" of a system?; What is a pool of a system?; What is a zero point?; or How do you achieve a linear description form in a non-linear system?

In addition, to collect information on students' satisfaction on educational factors that promote or hinder retention and transfer, a structured Likert-scale questionnaire consisting of 14 questions was developed. The selection of the questions to gather perceptions on factors influencing retention and transfer 
were inspired by the research on classroom climate and management (Stromei, 2002; Lee et al., 2019). Also, questions from the university evaluation questionnaires were used to compose the questionnaire. Questions focused on educational form i.e. lectures and instructions for traditional courses, and working groups, hands-on and experiments to support understanding; feedback and the assignments, that may influence quality of education, and consequently, may also facilitate retention and transfer.

For each cohort a focus group was conducted with small numbers of participating students comprising six to 10 students. The aim was to gather students' visions of what works and what specific aspects support retention and transfer according to the students. Questions were related to differences in the educational forms, i.e. traditional lectures versus work activities, and whether this created an impact on students' study habits, performance, interest of motivation.

\subsection{Selection of Participants}

All students enrolled in the 2015-2018 Systems and Control courses, and in the Signals and Systems project were approached to consider voluntarily participating in this study. To encourage participation a financial remuneration of 25 euro was offered to the students. Table 2 provides an overview of the students participating in this study in academic cohorts.

\section{Results}

In this section, the results of the three research questions we formulated for this study: RQ1-To what extent does the DBL approach facilitate the retention of concepts of control technology in comparison to the traditional course Signal and Systems?; RQ2-How do students perceive educational factors that may facilitate retention and transfer?; RQ3-What are students' perceptions about the factors that influence retention and transfer?

\subsection{Results of Retention and Transfer Assignments}

RQ1-To what extent does the DBL approach facilitate the retention of concepts of control technology in comparison to the traditional course Signal and Systems?

The students' results of the traditional course with the first cohort of DBL students were compared. The test consisted of 15 open short assignments in which

Table 2. Overview participants of this study in academic cohorts.

\begin{tabular}{cccc}
\hline Year & $\begin{array}{c}\text { Number of } \\
\text { students in the cohort }\end{array}$ & $\begin{array}{c}\text { Number of } \\
\text { students participating }\end{array}$ & $\begin{array}{c}\text { Percentage of } \\
\text { students from each year }\end{array}$ \\
\hline $2015 / 2016$ & 178 & $\mathrm{~N}=9$ & $5 \%$ \\
$2016 / 2017$ & 194 & $\mathrm{~N}=25$ & $12 \%$ \\
$2017 / 2018$ & 177 & $\mathrm{~N}=6$ & $3 \%$ \\
$2018 / 2019$ & 176 & $\mathrm{~N}=10$ & $5 \%$ \\
\hline
\end{tabular}


students had to answer questions and solve problems, and two general questions ( $\mathrm{N}=17$ questions). The assignments comprised exercises on systems and control technology, on measuring parameters (controllable-input) and readable-output, drafting a model of the open loop system (i.e. without closed loop control action) in a mathematical representation using differential equations and subject this to the Laplace transform, and to perform simulations in Simulink. The assignment consisting of questions 2 through 13 contain disciplinary character about control systems and are meant to test retention of knowledge, while question 14 has a transfer purpose, being question 15 a general question. The assignments were analysed and an overview of the frequencies in which the various points $(1-10)$ occur (see Figure 3 and Figure 4, scores refer to only questions 2 to 13$)$.

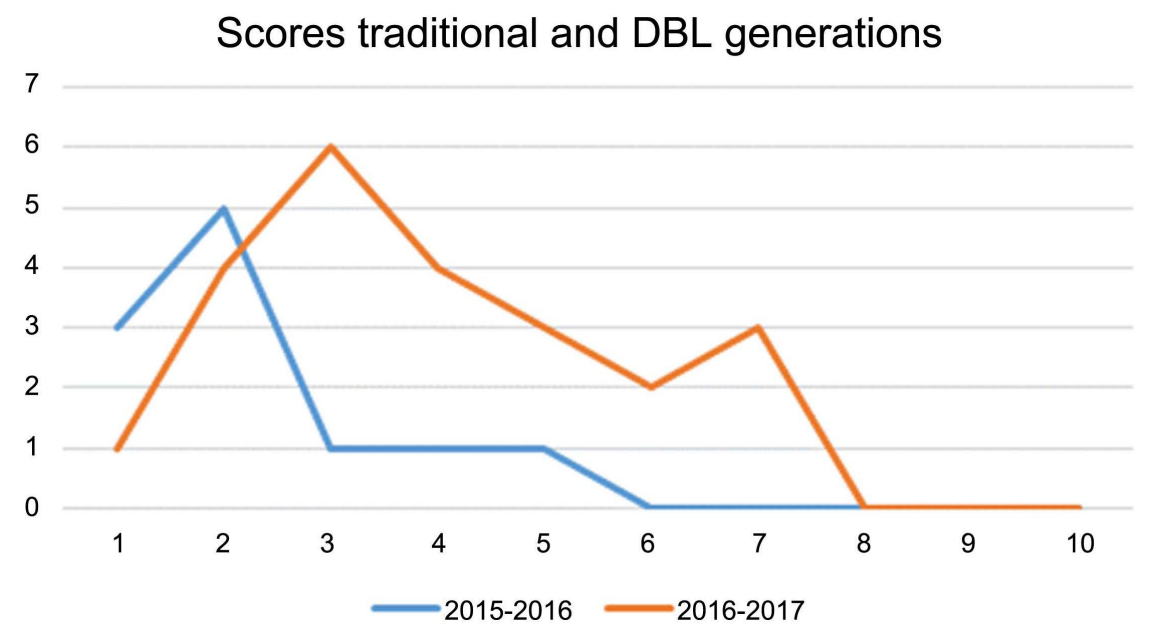

Figure 3. Overview of students' results of traditional versus DBL methods. Cohorts $2015 / 2016$ and $2016 / 2017 .{ }^{*} \mathrm{X}$-axis represents the average score, and $y$-axis is the frequency of how often the different scores happened $(1-10)$.

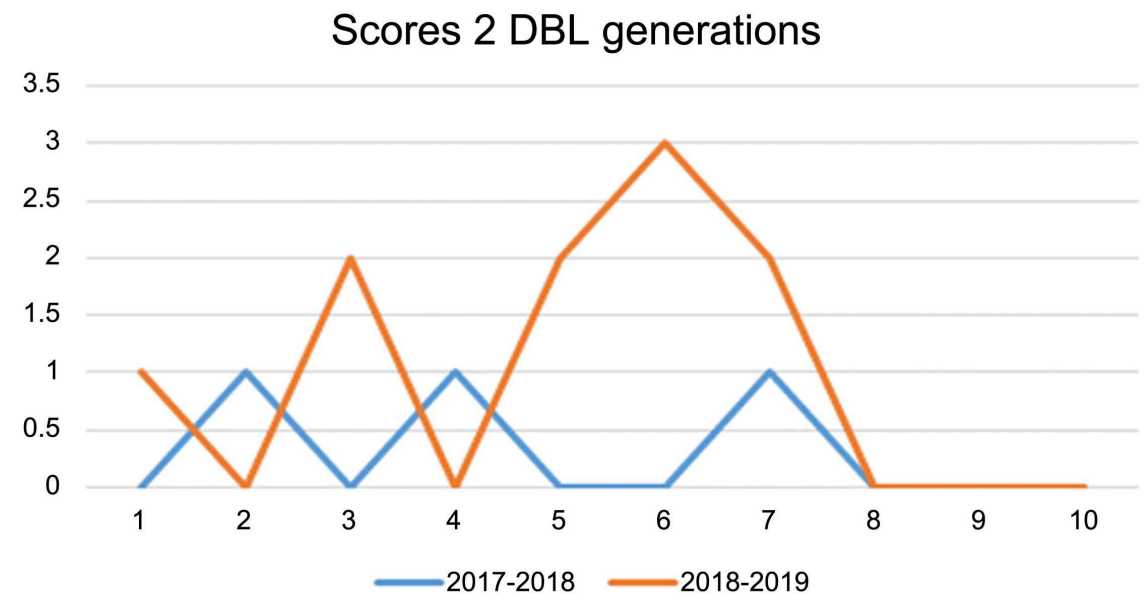

Figure 4. Overview of students' results of two DBL groups. Cohorts 2017/2018 and $2018 / 2019$. ${ }^{*} \mathrm{X}$-axis represents the average score, and $\mathrm{y}$-axis is the frequency of how often the different scores happened $(1-10)$. 
The results indicate difference between the two cohorts (traditional 2015/2016 versus DBL 2016/2017 cohorts), scoring the second cohort (DBL students) better than the traditional one.

Both DBL project approaches (cohorts 2017/2018 and 2018/2019) were also compared (Figure 4). The project instructional design included little differences in the set-up of the DBL project. A mid-term individual test was added to the DBL project in 2018/2019 as the only new added component. Tests' results indicate little differences between these two cohorts. In general, it was perceived that the overall average score was very similar between these two last DBL cohorts with an average grade of 7.0 being the highest score of a student of the DBL $2017 / 2018$ cohort. Looking at the individual results per question, it was not perceived that the young DBL cohort (2018/2019) gained higher grades in each individual question than the previous cohort (2017/2018). It is worth mentioning that the differences cannot be statistically proved due to the little number of students participating in this study.

The cohort 2018/2019 had an individual test for the first time causing a higher median (4.72) with respect to the cohort 2017/2018 (4.26). Regarding the traditional versus the first DBL project, the cohort 2015/2016 had a median of 2.28 median, while the cohort $2016 / 2017$ had 4.09 as a median value.

Based on these findings, the transition from classic to DBL caused an increase in the median of about 2.5 points (from 2.28 to 4.26 ). When comparing the three DBL cohorts the differences of $4.09,4.26$ and 4.72 respectively, were not observed. Regarding the last DBL year in which an interim test was included, the median increased up to 4.72 . With respect to the latest cohort, it was important to assume that the increase in the median was caused by the interim test as this test took place in week 3 in an organization of the project consisting of a total of an 8-weeks block. It was therefore assumed that the students had not yet gained all the knowledge expected in the entire block and the students' average score 7.1 in the interim electronic test.

Careful observations were that the results of these assignments of the four different cohorts of students following the Signals \& Systems project either the traditional course or the DBL project approach, did not show a loss in knowledge, and therefore according to the definition in this study, there was no loss in retention.

In terms of transfer (Question 14), students were expected to apply the features of a control system to identify the input and output rather than just applying knowledge of the system learned in the course (floating ball). In this question, students were required to transfer knowledge in a new context. It was expected therefore that students take distance from the subject matter learned in order to analyze another system than the floating ball. The results reported that the students were able to use the knowledge gained in the DBL projects (Mean 3.09; 3.0; and 3.6 respectively in DBL cohorts) more effectively than in traditional courses (2.18 in cohort 2015/2016) in solving similar problems in a new and different context. 
Regarding Question 15, the results showed that all cohorts had scored the same average (Mean 3.0) and no major differences were appreciated. In addition, the pass rates of all cohorts of students following the different iterations of the course were compared (see Table 3 ). The pass rate of the DBL courses was higher than in the traditional course. This difference could be justified by the fact that the assessment of the traditional course was entirely based on individual assessment while in the DBL project most of the grade is based on group assessment with some small individual components (Table 1).

Despite the results provided in this study, it is worth noting that the number of students participating in the research is limited as participation was voluntary. Therefore, the research findings are unable to support strong statements on the impact of this study on retention and learning standard knowledge motivated by the use of design-based learning methods. Also, the time that students took to do the retention test between cohorts was not the same, therefore, the retention and transfer level in a traditional compared to a design-based learning course cannot be fully compared.

\subsection{Results Students' Perceptions}

RQ2-What are the educational factors as perceived by the students that may facilitate retention and transfer?

Regarding the research question about the educational factors that may facilitate retention and transfer, perceptions of students from cohort attending the traditional Systems and Control course (2015/2016) indicate that the educational form i.e. lectures, instructions, practical work in a lab, support understanding (see Table 4).

However, comparing these results with the students' perceptions about the Signals and Systems DBL project (2016/2017), there were no substantial differences in the different items of the survey. The educational elements included in the first DBL project (i.e. hands-on approach by doing research-experimenting and group presentations, supervision and feedback by tutors), score much lower than the means of the traditional Systems and Control. Students' means in this cohort reflected that "doing exercises has not supported the understanding (more) than the group work" and "assignments and exercises practiced during the group work helped apply the knowledge" did not contribute greatly to gain a deeper understanding. The difference in scores may be explained by the fact that this was the first time the DBL project was designed as such and some adjustments in the set-up of the course were needed.

Table 3. Overview pass rates different cohorts.

\begin{tabular}{ccc}
\hline Year & \% Pass rate & Average grade \\
\hline $2015 / 2016$ & 88 & 7.66 \\
$2016 / 2017$ & 100 & 7.46 \\
$2017 / 2018$ & 100 & 7.52 \\
$2018 / 2019$ & 100 & 7.31 \\
\hline
\end{tabular}


Table 4. Overview students' perceptions in means along different cohorts.

\begin{tabular}{|c|c|c|c|c|c|c|c|c|}
\hline Cohort & $2015 / 201$ & & $2016 / 2017$ & & $2017 / 2018$ & & $2018 / 201$ & \\
\hline Survey questions & Mean & $\mathrm{SD}$ & Mean & $\mathrm{SD}$ & Mean & $\mathrm{SD}$ & Mean & $\mathrm{SD}$ \\
\hline $\begin{array}{l}\text { 1) This educational form (group work) contributed to my } \\
\text { understanding of the subject matter/concepts.* }\end{array}$ & 4.00 & 0.86 & 2.68 & 0.82 & 3.50 & 1.51 & 3.40 & 1.17 \\
\hline $\begin{array}{l}\text { 2) This educational form (doing research-experimenting) } \\
\text { contributed to my understanding of the subject matter/concepts. }{ }^{* *}\end{array}$ & 3.33 & 0.70 & 2.56 & 0.82 & 2.66 & 1.16 & 3.90 & 0.87 \\
\hline $\begin{array}{l}\text { 3) This educational form (presentations for the group/lab } \\
\text { work/discussions) contributed to my understanding of the subject } \\
\text { matter/concepts. }{ }^{* *}\end{array}$ & 3.88 & 0.78 & 3.28 & 0.97 & 3.07 & 1.37 & 3.10 & 1.52 \\
\hline 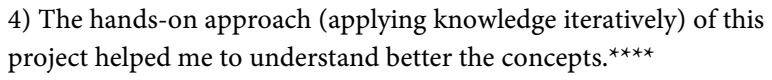 & 3.55 & 0.52 & 2.76 & 0.72 & 4.01 & 0.98 & 3.80 & 1.31 \\
\hline $\begin{array}{l}\text { 5) Doing exercises helped me understand better the concepts than } \\
\text { group work. }\end{array}$ & 3.44 & 0.52 & 2.84 & 0.74 & 3.72 & 1.03 & 3.20 & 1.2 \\
\hline $\begin{array}{l}\text { 6) The assignments/exercises practiced during the group work } \\
\text { helped apply knowledge I knew. }\end{array}$ & 3.55 & 0.52 & 2.76 & 0.72 & 3.53 & 0.81 & 3.11 & 0.92 \\
\hline $\begin{array}{l}\text { 7) The feedback I received during the groupwork helped me } \\
\text { understand the subject better/concepts. }\end{array}$ & 3.22 & 0.97 & 2.92 & 0.86 & 3.36 & 1.63 & 3.20 & 1.39 \\
\hline
\end{tabular}

For the purpose of this research, we report only about the students' perceptions on 7 items of the structured questions relevant to our study. Cohort of students 2015/2016 followed a traditional course consisting of lectures, instructions and practical assignments in a lab. Questions for this cohort were slightly different: ${ }^{*}$ This educational form (lectures) contributed to my understanding of the subject matter. ${ }^{*}$ This educational form (instructions) contributed to my understanding of the subject matter. ${ }^{* *}$ This educational form (practical work in a lab) contributed to my understanding of the subject matter.

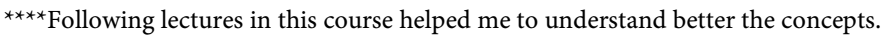

However, the analysis of the students' perceptions of the DBL project after the second iteration in 2017/2018 including some educational adjustments and the interdisciplinary elements, revealed a higher level of satisfaction. This showed that the higher means in educational factors i.e. doing research-experimenting, group presentations, lab work, discussions, the hands-on approach, were related to feedback. These are also active learning factors that may be considered can play an important role in supporting retention and transfer.

Students from this cohort part of the Innovation Space pilot had not perceived the educational form (doing research-experimenting) as a factor contributing to a better understanding of concepts and subject matter. Finally, the means of the last iteration of the Signals and Systems project (2018/2019) in which individual interim assessment was introduced, were higher than in previous academic years as observed in Table 4.

The scores on the educational factors of the Signals and Systems project with those of a traditional course were also correlated. For this purpose, the items This educational form (group work) contributed to my understanding of the subject matter/concepts; This educational form (doing research-experimenting) contributed to my understanding of the subject matter/concepts; Doing exercises help me to understand better the concepts than group work; This educational form (presentations for the group/lab work/discussions) contributed to my understanding of the subject matter/concepts; The assignments/exercises practiced during the group work helped apply knowledge I knew; The feedback I received 
during the groupwork helped me understand the subject better/concepts) of the students' survey attending the traditional course and correlated those with the DBL project carried out in the last year. The assumption was that educational factors facilitating retention in traditional courses also facilitate this with active learning approaches. Results revealed that there is little correlation between these educational factors $\left(R^{2}\right.$ linear $\left.=0.045\right)$.

\subsection{Students' Perceptions on Factors Influencing Retention and Transfer}

RQ3-What are students' perceptions about the factors that influence retention and transfer?

Interviews in focus groups with the students were conducted to validate the educational factors that enhanced learning and conceptual understanding that may also stimulate retention and transfer, and clear patterns were found throughout all cohorts.

Students attending the traditional course perceived that repetition of topics throughout other courses in the bachelor was a key element that help deep and longer understanding of subjects. However, the content of the Systems and Control was not provided in successive courses in the bachelor and this was identified as a shortcoming that hindered retention. In addition, practice helped retain knowledge and facilitated a better understanding of the subject matter, that could be later applied in solving exercises in other courses. Finally, feedback and explanations on exercises during instructions were what definitively could facilitate understanding and therefore retention.

For the first cohort of students exposed to the DBL project, retention would be gained by repetition of topics throughout bachelor courses; by doing exercises, and finally, by individual assessment and when there were possibilities to work on own design (individual contribution to project). The factors related to individual components were not part of this DBL project and therefore this could explain the low scores in students' perceptions in this cohort.

Students from the last two cohorts (2017/2018 and 2018/2019) participating in the study noted that the most critical factors that promote retention were good explanations by the teachers and practice. Practice assures that students remain in contact with the content as they use theory to apply in the projects. Also motivating tutors that supervised students was perceived as an added value, although they preferred the feedback from the teachers as this included more content-oriented feedback. In addition, students observed that if the project was challenging and individual components were included, these could also be factors stimulating retention and transfer.

\section{Discussion and Limitations of This Study and Future Research}

Literature indicates the added value of active learning that facilitates retention and transfer of knowledge (Bransford \& Schwartz, 1999; Crouch \& Mazur, 2001; 
Cummings, Lockwood, \& Marx, 2004). This study investigated how a design-based learning project that included challenging assignments for students, supports the retention of knowledge and transfer more than a traditional course. These results are in line with research on the approaches that bring on deep learning and promote retention.

However, caution needs to be added to confirm the findings with certainty as the experiment conducted in the last two DBL cohorts did not provide significant results to make strong statements. Due to the fact that there was a small number of students participating in this study meant that the study was not representative and therefore the results do not allow to make decisive conclusions. This study sheds light in view of learning environments such as design-based learning that lie in the engineering and science education research. The challenge-oriented assignments engage students in authentic assignments with open-ended and hands-on tasks that facilitate the use of knowledge learned in previous courses and support the transfer into new contexts.

\section{Conclusion}

The initial purpose of this study was to investigate whether traditional educational form of the course Systems and Control enhances retention and transfer as the design-based Signals and Systems challenge-based learning project does. The design-based learning project Signals and Systems with challenging tasks supported students to retain and transfer subject matter in solving problems in a different context more than the traditional version of the course. These findings support the scientific research in this field that indicates that active learning methods facilitate learning and more specifically the understanding of physics concepts. The results of this study also shed light and reinforce the body of knowledge regarding the literature on project-based, design-based and alike approaches. The significance of this study is additionally relevant as challenging assignments in design-based learning projects are not frequently studied.

Moreover, the fact that students' perceptions on educational factors were similar when comparing the traditional course as well as the DBL projects implemented in the last two years, shows that students were satisfied with both educational approaches as a means to facilitate retention and transfer.

Regarding the educational factors, students from all cohorts agreed that repeating the content in different courses through the bachelor years, together with practicing and doing exercises, and receiving feedback are the elements supporting retention and transfer. These are nevertheless educational elements essential to maintaining quality of education.

The study findings conclude that design-based learning including challenging tasks is suitable active learning method that helps facilitate retention and transfer of knowledge.

\section{Acknowledgements}

We would like to thank all students from the Applied Physics department who 
have participated in this study. Their contribution was extremely valuable to understand the benefits of how active learning approaches such as challenge-based and design-oriented approaches can have on education and students.

\section{Conflicts of Interest}

The authors declare no conflicts of interest regarding the publication of this paper.

\section{References}

Adams, L., Kasserman, J., Yearwood, A., Perfetto, G., Bransford, J., \& Franks, J. (1988). The Effects of Facts versus Problem-Oriented Acquisition. Memory \& Cognition, 16, 167-175. https://doi.org/10.3758/BF03213486

Anderson, J. R., Reder, L. M., \& Simon, H. A. (1997). Rejoinder: Situative versus Cognitive Perspectives: Form versus Substance. Educational Researcher, 26, 18-21. https://doi.org/10.2307/1176868

Apedoe, X. A., Reynolds, B., Ellefson, M. R., \& Schunn, C. D. (2008). Bringing Engineering Design into High School Science Classrooms: The Heating/Cooling Unit. Journal of Science Education and Technology, 17, 454-465.

https://doi.org/10.1007/s10956-008-9114-6

Atman, C. J., Adams, R. S., Cardella, M. E., Turns, J., Mosborg, S., \& Saleem, J. (2007). Engineering Design Processes: A Comparison of Students and Expert Practitioners. Journal of Engineering Education, 96, 359-379. https://doi.org/10.1002/j.2168-9830.2007.tb00945.x

Bacon, D. R., \& Stewart, K. A. (2006). How Fast Do Students Forget What They Learn in Consumer Behavior? A Longitudinal Study. Journal of Marketing Education, 28, 181-192. https://doi.org/10.1177/0273475306291463

Barron, B. J., Schwartz, D. L., Vye, N. J., Moore, A., Petrosino, A., Zech, L., Bransford, J. D., \& CTGV (1998). Doing with Understanding: Lessons from Research on Problem and Project-Based Learning. Journal of Learning Sciences, 7, 271-312. https://doi.org/10.1080/10508406.1998.9672056

Behrens, A., Atorf, L., Schwann, R., Neumann, B., Schnitzler, R., \& Balle, J. (2010). MATLAB Meets LEGO Mindstorms-A Freshman Introduction Course into Practical Engineering. IEEE Transactions on Education, 53, 306-317. https://doi.org/10.1109/TE.2009.2017272

Bjork, R. A., \& Richardson-Klavhen, A. (1989). On the Puzzling Relationship between Environment Context and Human Memory. In C. Izawa (Ed.), Current Issues in Cognitive Processes: The Tulane Flowerree Symposium on Cognition (pp. 313-344). Hillsdale, NJ: Erlbaum.

Bransford, J. D., \& Schwartz, D. L. (1999). Rethinking Transfer: A Simple Proposal with Multiple Implications. Review of Research in Education, 24, 61-100. https://doi.org/10.2307/1167267

Bransford, J. D., Zech, L., Schwartz, D., Barron, B., Vye, N., \& CTGV (1999). Designs for Environments That Invite and Sustain Mathematical Thinking. In P. Cobb (Ed.), Symbolizing, Communicating, and Mathematizing: Perspectives on Discourse, Tools, and Instructional Design (pp. 275-324). Mahwah, NJ: Lawrence Erlbaum Associates.

Chang, G.-W., Yeh, Z.-M., Pan, S.-Y., Liao, C.-C., \& Chang, H.-M. (2008). A Progressive Design Approach to Enhance Project-Based Learning in Applied Electronics through 
an Optoelectronic Sensing Project. IEEE Transaction on Education, 51, 220-233. https://doi.org/10.1109/TE.2007.907321

Chase, C., Malkiewich, L., \& Kumar, A. S. (2019). Learning to Notice Science Concepts in Engineering Activities and Transfer Situations. Science Education, 103, 440-471. https://doi.org/10.1002/sce.21496

Crouch, C., \& Mazur, E. (2001). Peer Instruction: Ten Years of Experience and Results. American Journal of Physics, 69, 970-977. https://doi.org/10.1119/1.1374249

Cummings, K., Lockwood, S., \& Marx, J. (2004). Attitudes toward Problem Solving as Predictors of Student Success. AIP Conference Proceedings, 720, 133-136. https://doi.org/10.1063/1.1807272

Denayer, I., Thaels, K., Vander Sloten, J., \& Gobin, R. (2003). Teaching a Structured Approach to the Design Process for Undergraduate Engineering Student by Problem-Based Education. European Journal of Engineering Education, 28, 203-214. https://doi.org/10.1080/0304379031000079031

Deslauriers, L., Schelew, E., \& Wieman, C. (2011). Improved Learning in Large-Enrollment Physics Class. Science, 332, 862-864. https://doi.org/10.1126/science.1201783

Direnga, J., Presentati, B., Timmermann, D., Brose, A., \& Kautz, C. (2015). Does It Stick? Investigating Long-Term Retention of Conceptual Knowledge in Mechanics Instruction. 122nd ASEE Annual Conference \& Exposition, Seattle, 14-17 June 2015, Paper ID: \#13219. https://doi.org/10.18260/p.23897

Doppelt, Y., Mehalik, M. M., Schunn, C. D., Silk, E., \& Krysinski, D. (2008). Engagement and Achievements: A Case Study of Design-Based Learning in a Science Context. Journal of Technology Education, 19, 22-39.

Dym, C., \& Little, P. (2003). Engineering Design: A Project-Based Introduction (2nd ed.).

Dym, C., Agogino, A., Eris, O., \& Leifer, L. (2003). Engineering Design Thinking, Teaching, and Learning. Journal of Engineering Education, 94, 103-120. https://doi.org/10.1002/j.2168-9830.2005.tb00832.x

Elby, A. (2001). A Helping Physics Students Learn How to Learn. American Journal of Physics, 69, 54-64. https://doi.org/10.1119/1.1377283

Etkina, E., Karelina, A., Ruibal-Villasenor, M., Rosengrant, D., Jordan, R., \& Hmelo-Silver, C. E. (2010). Design and Reflection Help Students Develop Scientific Abilities: Learning in Introductory Physics Laboratories. Journal of the Learning Sciences, 19, 54-98. https://doi.org/10.1080/10508400903452876

Etkina, E., Murthy, S., \& Zou, X. (2006). Using Introductory Labs to Engage Students in Experimental Design. American Journal of Physics, 74, 979-986.

https://doi.org/10.1119/1.2238885

Fortus, D., Dershimer, R., Krajcik, J., Marx, R., \& Mamlok-Naaman, R. (2004). Design-Based Science and Student Learning. Journal of Research in Science Teaching, 41, 1081-1110. https://doi.org/10.1002/tea.20040

Gegenfurtner, A. (2013). Dimensions of Motivation to Transfer: A Longitudinal Analysis of Their Influence on Retention, Transfer, and Attitude Change. Vocations and Learning, 6, 187-205. https://doi.org/10.1007/s12186-012-9084-y

Gick, M. L., \& Holyoak, K. J. (1980). Analogical Problem Solving. Cognitive Psychology, 12, 306-355. https://doi.org/10.1016/0010-0285(80)90013-4

Gick, M. L., \& Holyoak, K. J. (1983). Schema Induction and Analogical Transfer. Cognitive Psychology, 15, 1-38. https://doi.org/10.1016/0010-0285(83)90002-6

Gómez Puente, S. M., van Eijck, M., \& Jochems, W. (2011). Towards Characterizing Design Based Learning in Engineering Education: A Review of the Literature. European 
Journal of Engineering Education, 36, 137-149.

https://doi.org/10.1080/03043797.2011.565116

Gómez Puente, S. M., van Eijck, M., \& Jochems, W. (2013). A Sampled Literature Review of Design Based Learning Approaches: A Search for Key Characteristics. International Journal of Technology and Design Education, 23, 717-732. https://doi.org/10.1007/s10798-012-9212-x

Gómez Puente, S. M., van Eijck, M., \& Jochems, W. (2014). Exploring the Effects of Design-Based Learning Characteristics on Teachers and Students. International Journal of Engineering Education, 30, 916-928.

Hake, R. (1998). Interactive-Engagement versus Traditional Methods: A Six-ThousandStudent Survey of Mechanics Test Data for Introductory Physics Courses. American Journal of Physics, 66, 64. https://doi.org/10.1119/1.18809

Jonassen, D. (2011). Supporting Problem Solving in PBL. Interdisciplinary Journal of Problem-Based Learning, 5, 95-119. https://doi.org/10.7771/1541-5015.1256

Jonassen, D. H. (2000). Toward a Design Theory of Problem Solving. Educational Technology Research and Development, 48, 63-85. https://doi.org/10.1007/BF02300500

Judd, C. H. (1908). The Relation of Special Training to General Intelligence. Educational Review, 36, 28-42.

Kang, S., McDermott, K. B., \& Roediger III, H. (2007). Test Format and Corrective Feedback Modify the Effect of Testing on Long-Term Retention. European Journal of Cognitive Psychology, 19, 528-558. https://doi.org/10.1080/09541440601056620

Karelina, A., \& Etkina, E. (2007) Acting like a Physicist: Student Approach Study to Experimental Design. Physical Review Special Topics-Physics Education Research, 3, Article ID: 020106. https://doi.org/10.1103/PhysRevSTPER.3.020106

Kirschner, P. A., Sweller, J., \& Clark, R. E. (2006). Why Minimal Guidance during Instruction Does Not Work: An Analysis of the Failure of Constructivist, Discovery, Problem-Based, Experiential, and Inquiry-Based Teaching. Educational Psychologist, 41, 75-86. https://doi.org/10.1207/s15326985ep4102_1

Kolodner, J. L. (2002). Learning by Design: Iterations of Design Challenges for Better Learning of Science Skills. Cognitive Studies, 9, 338-350.

Kolodner, J. L., Camp, P. J., Crismond, D., Fasse, B., Gray, J., Holbrook, J., Puntambekar, S., \& Ryan, M. (2003). Problem-Based Learning Meets Case-Based Reasoning in the Middle-School Science Classroom: Putting Learning by DesignTM into Practice. Journal of the Learning Sciences, 12, 495-547. https://doi.org/10.1207/S15327809JLS1204_2

Kryjevskaia, M., MacKenzie R. S., \& Grosz, N. (2014). Applying the Heuristic-Analytic Theory of Reasoning to Examine Student Intuitive Thinking in the Context of Physics. Physics Review - Physics Education Research, 10, Article ID: 020109. https://doi.org/10.1103/PhysRevSTPER.10.020109

Kunnen, R. P. J., Kroesen, G. M. W., \& Gómez Puente, S. M. (2018). Transforming Traditional Physics Courses into Challenged-Based Projects. Innovation Centers Academic Bèta Education (ICAB) Conference, Twente. https://www.utwente.nl/en/tnw/icab/

Lamancusa, J. S. (2006). Design as the Bridge between Theory and Practice. International Journal of Engineering Education, 22, 652-658.

Larsen-Freeman, D. (2013). Transfer of Learning Transformed. Language Learning, 63, 107-129.

Lawson, B., \& Dorst, K. (2009). Design Expertise. Oxford: Architectural Press.

Lee, A. Y. (1998). Transfer as a Measure of Intellectual Functioning. In S. Soraci, \& W. J. McIlvane (Eds.), Perspectives on Fundamental Processes in Intellectual Functioning: A 
Survey of Research Approaches (pp. 351-366). Stamford, CT: Ablex.

Lee, Y., Yang, H. H., MacLeod, J., \& Dai, J. (2019). Developing the Rotational Synchronous Teaching (RST) Model: Examination of the Connected Classroom Climate. Australasian Journal of Educational Technology, 35, 116.

Lucas, K., Testman, J., Hoyland, N., Kimble, A., \& Euler, M. (2013). Correlation between Active-Learning Coursework and Student Retention of Core Content during Advanced Pharmacy Practice Experiences. American Journal of Pharmaceutical Education, 77, 171. https://doi.org/10.5688/ajpe778171

Malmqvist, J., Rådberg, K. K., \& Lundqvist, U. (2015). Proceedings of the 11th International CDIO Conference, Chengdu University of Information Technology, Chengdu, Sichuan, P.R. China, June 8-11, 2015.

Martínez Monés, A., Gómez Sánchez, E., Dimitriadis, Y. A., Jorrín Abellán, I. M., \& Rubia Avi, B. (2005) Multiple Case Studies to Enhance Project-Based Learning in a Computer Architecture Course. IEEE Transactions on Education, 48, 482-488. https://doi.org/10.1109/TE.2005.849754

Marx, J., \& Cummings, K. (2007). What Factors Really Influence Shifts in Students' Attitudes and Expectations in an Introductory Physics Course? Proceedings of the 2006 Physics Education Research Conference, Syracuse, 26-27 July 2006, 101-104. https://doi.org/10.1063/1.2508701

Mason, A., \& Singh, C. (2010). Do Advanced Physics Students Learn from Their Mistakes without Explicit Intervention? American Journal of Physics, 78, 760. https://doi.org/10.1119/1.3318805

Mason, A., Cohen, E., Yerushalmi, E., \& Singh, C. (2008). Identifying Differences in Diagnostic Skills between Physics Students: Developing a Rubric. Proceedings of the Physics Education Research Conference, Vol. 1064, 147-150. https://doi.org/10.1063/1.3021239

Mazur, E. (2009). Farewell, Lecture? Science, 323, 50. https://doi.org/10.1126/science.1168927

McConnell, D. A., Steer, D. N., Owens, K. D., Knott, J. R., Van Horn, S., Borowski, W., Dick, J., Foos, A., Malone, M., McGrew, H., Greer, L., \& Heaney, P. J. (2006). Using ConcepTests to Assess and Improve Student Conceptual Understanding in Introductory Geoscience Courses. Journal of Geoscience Education, 54, 61-68. https://doi.org/10.5408/1089-9995-54.1.61

McCusker, K., \& Gunaydin, S. (2015). Research Using Qualitative, Quantitative or Mixed Methods and Choice Based on the Research. Perfusion, 30, 537-542. https://doi.org/10.1177/0267659114559116

McKagan, S. B., \& Wieman, C. E. (2006). Exploring Student Understanding of Energy through the Quantum Mechanics Conceptual Survey. AIP Conference Proceedings, 818, 65-68. https://doi.org/10.1063/1.2177024 http://per.colorado.edu/QMCS

McKeough, A., Lupart, J., \& Marini, A. (1995). Teaching for Transfer: Fostering Generalization in Learning (pp. 35-68). Hillsdale, NJ: Lawrence Erlbaum Associates, Inc.

Mehalik, M. M., \& Schunn, C. (2006). What Constitutes Good Design? A Review of Empirical Studies of Design Processes. International Journal of Engineering Education, 22, 519-532.

Mehalik, M. M., Doppelt, Y., \& Schunn, C. D. (2008). Middle School Science through Design-Based Learning versus Scripted Inquiry: Better Overall Science Concept Learning and Equity Gap Reduction. Journal of Engineering Education, 97, 71-85. https://doi.org/10.1002/j.2168-9830.2008.tb00955.x 
Miller, K., Lasry, N., Chu, K., \& Mazur, E. (2013). Role of Physics Lecture Demonstrations in Conceptual Learning. Physics Review-Physics Education Research, 9, Article ID: 020113. https://doi.org/10.1103/PhysRevSTPER.9.020113

Moreno, R. (2004). Decreasing Cognitive Load in Novice Students: Effects of Explanatory versus Corrective Feedback in Discovery-Based Multimedia. Instructional Science, 32, 99-113. https://doi.org/10.1023/B:TRUC.0000021811.66966.1d

Ozimek, D. J., Engelhardt, P. V., Bennett, A. G., \& Rebello, N. S. (2005). Retention and Transfer from Trigonometry to Physics. AIP Conference Proceedings, 790, 173. https://doi.org/10.1063/1.2084729

Plonsky, L., \& Gass, S. (2011). Quantitative Research Methods, Study Quality, and Outcomes: The Case of Interaction Research. East Lansing, MI: Michigan State University. https://doi.org/10.1111/j.1467-9922.2011.00640.x

Prince, M. (2004). Does Active Learning Work? A Review of the Research. Journal Engineering Education, 93, 223-231. https://doi.org/10.1002/j.2168-9830.2004.tb00809.x

Sheppard, S. D., Macatangay, K., Colby, A., \& Sullivan, W. (2008). Educating Engineers: Designing for the Future of the Field. Stanford, CA: Jossey-Bass.

Singh, C. (2002). When Physical Intuition Fails. American Journal of Physics, 70, 1103-1109.

Singley, K., \& Anderson, J. R. (1989). The Transfer of Cognitive Skills. Cambridge, MA: Harvard University Press.

Spiro, R. J., Vispoel, W. P., Thorndike, E. L., \& Woodworth, R. S. (1901). The Influence of Improvement in One Mental Function upon the Efficacy of Other Functions. Psychological Review, 8, 247-261. https://doi.org/10.1037/h0074898

Stromei, L. K. (2002). Increasing Retention and Success through Mentoring. New Directions for Communities Colleges, 2000, 55-62. https://doi.org/10.1002/cc.11205

Svensson, M. (2016). Learning about Systems. In M. de Vries (Ed.), Handbook of Technology Education (pp. 447-462). Springer International Handbooks of Education, Cham: Springer. https://doi.org/10.1007/978-3-319-44687-5_34

Tew, A. E., \& Guzdial, M. (2010). Developing a Validated Assessment of Fundamental CS1 Concepts. Proceedings of the 41st SIGCSE Technical Symposium on Computer Science Education, Milwaukee, 10-13 March 2010, 97-101. https://doi.org/10.1145/1734263.1734297

Tight, M. (2020). Student Retention and Engagement in Higher Education. Journal of Further and Higher Education, 44, 689-704. https://doi.org/10.1080/0309877X.2019.1576860

Veermans, K., van Joolingen, W., \& de Jong, T. (2006). Use of Heuristics to Facilitate Scientific Discovery Learning in a Simulation Learning Environment in a Physics Domain. International Journal of Science Education, 28, 341-361. https://doi.org/10.1080/09500690500277615

Wertheimer, M. (1959). Productive Thinking. New York: Harper and Row.

Wijnen, W. H. F. W. (2000). Towards Design-Based Learning. Eindhoven: Eindhoven University of Technology Educational Service Centre. 


\section{Appendix: Retention and Transfer Assignment}

1) In which year did you take the course?

a) $2015-2016$

b) $2016-2017$

c) $2017-2018$

d) 2018-2019

2) What are the steps that must be followed in succession to design a control system?

3) What is THE characteristic element of the I component in a control system?

4) What are the effects of increasing the proportional action with a P scheme?

5) What is meant by a system's "open-loop transfer function"?

6) What is a pool of a system?

7) What is a zero point?

8) How do you achieve a linear form of description with a non-linear system?

9) What is a Root-Locus plot?

10) What is a Bode diagram?

11) Where should the poles of a closed control system lie if the situation is to be stable?

12) What ways do you remember to "move" with poles?

13) What benefits can a Simulink-Matlab environment offer to a control engineer?

14) A control system already has essential components an input signal and an output signal) Describe the two components for the following situations:

a) The cruise control of a car

b) A toilet bowl

c) A central heating thermostat

d) The "floating ball" of the Practicum of OGO

15) Name three more examples of control systems in your daily life.

16) Did you enjoy taking the course?

17) Did you find the content relevant for your further career development? 